\title{
EL NUEVO AEROPUERTO Y LA DEFENSA DEL territorio en Atenco-Texcoco, México. USOS POLÍTICOS Y RESGUARDOS SOCIALES DE LA CULTURA ACOLHUA A TRAVÉS DE LA HISTORIA
}

The new airport and the defense of territory in Atenco-Texcoco, Mexico. Political uses and social reservoirs of Acolhua culture through history.

\author{
Itzam Pineda Rebolledo \\ itzam.pineda@uacm.edu.mx \\ Antropólogo social
}

RESUMEN: El debate actual sobre los derechos culturales en las ciencias sociales latinoamericanas, se inserta necesariamente en el contexto de las disputas territoriales que en todo el continente ha desatado la oleada de megaproyectos contra los pueblos originarios. Sin embargo, debido a la naturaleza de los instrumentos legales existentes para este fin, en estas situaciones los pueblos se ven obligados a demostrar su identidad indígena ante los tribunales. Si bien, las nociones esencialistas sobre los sentidos de pertenencia han sido trascendidas en los estudios disciplinares por las perspectivas relacionales, el avance de los procesos de urbanización ha generado contextos complejos y dinámicos en los que se vuelve indispensable la revisión de las categorías de este nudo problemático. En este trabajo proponemos analizar los usos políticos y resguardos sociales de las prácticas culturales vinculándolos a los procesos sociohistóricos que protagonizan los pueblos en la defensa de su territorio y apartándonos de las explicaciones substancialistas. El contexto de este análisis en particular, es el trabajo antropológico de acompañamiento al proceso legal de los pueblos de Atenco-Texcoco, vecinos próximos a la capital del país que defienden su territorio de las afectaciones provocadas por la construcción del Nuevo Aeropuerto de la Ciudad de México.

PalABras ClaVe: urbanización, megaproyectos, territorio, indígenas, derechos culturales. 


\begin{abstract}
The current debate on cultural rights in Latin American social sciences is necessarily framed in the context of the defense of territory which has broken out in the continent in the wake of the mega-projects against Native peoples. However, due to the nature of existing legal instruments, in these situations indigenous peoples are forced to prove their "indigenous identity" in court. Although essentialist notions of the meanings of belonging have been transcended in research in the discipline, as relational perspectives have emerged, the rapid processes of urbanization have generated complex contexts and dynamics in which it becomes crucial to rethink the categories used to approach this thorny problem. In this article, we analyze the political uses and social reservoirs of cultural practices, by linking them to socio-historical processes led by communities in the defense of their territory, leaving aside substantialist explanations. This particular analysis was developed through ongoing anthropological teamwork accompanying the legal process led by the Texcoco-Atenco communities around the Mexican capital while defending their territory from the negative consequences of the construction of the new airport of Mexico City.
\end{abstract}

KEYWORDS: urbanization, megaprojects, territory, indigenous peoples, cultural rights.

L uego de tres décadas de aplicación continua de políticas neoliberales, que han implicado entre otras cosas, la legalización de la privatización a la propiedad colectiva de la tierra, el abandono por parte de la estructura estatal a las actividades productivas campesinas y la apertura de la frontera a los mercados y capitales, sobre todo norteamericanos, a través de las disposiciones del Tratado de Libre Comercio para América del Norte (TLCAN), México experimenta actualmente un amplio proceso de territorialización del capital. Extensas regiones en todo el país se encuentran bajo la presión de proyectos extractivistas e inmobiliarios que se ciernen sobre la vida cotidiana de cientos de comunidades en el medio rural, generalmente pueblos originarios y en la periferia de las ciudades. Es necesario señalar que las obras proyectadas, sean éstas de índole minero, energético o de infraestructura, al cabo de las primeras etapas permiten a sus promotores, cobijados también por 
la venia de las autoridades civiles, la presentación de sus intenciones urbanizadoras. Es así que, en la narrativa de los habitantes de las regiones, a la intromisión de las compañías contratistas en sus territorios, generalmente sin autorización comunitaria, sigue la promesa de obras de servicios urbanos.

El fenómeno ha provocado cientos de conflictos socioambientales y la interposición de demandas legales por parte de los pueblos afectados para detener el avance de las obras. Una de las estrategias que los pueblos han seguido es alinearse a los derechos colectivos y culturales que diversos instrumentos jurídicos, tanto nacionales como internacionales permiten invocar en su defensa del territorio. Uno de los instrumentos más empleados es el Convenio 169 de la Organización Internacional del Trabajo (ОIт) cuyo principal criterio de cobertura es la autoadscripción de los pueblos. Es en este contexto que el debate en México sobre los derechos culturales de los pueblos y su calidad indígena, étnica y originaria ha adquirido relevancia en ámbitos tan diversos como el local, el jurídico, el académico e incluso el político y mediático.

Este texto no pretende llegar al establecimiento de generalizaciones que homogenicen la situación actual de los pueblos, las rutas en torno a la defensa de sus derechos y las complejidades de sus identidades en un país y mucho menos en un continente. Se trata de exponer algunas reflexiones sobre el uso político (Dubet, 1989) y resguardo social ${ }^{1}$ de su identidad en un contexto determinado. Los planteamientos se desprenden del trabajo de soporte antropológico a la ruta jurídica iniciada por diversos pueblos de la Cuenca de México. Hacemos aquí una propuesta analítica en torno a una región presionada por un proyecto aeroportuario en donde uno de los elementos en disputa es precisamente su autoadscripción cultural (en términos jurídicos), su etnicidad (en términos antropológicos), esgrimida en medio de un litigio por parte de sus habitantes en la defensa de su territorio. Proponemos el estudio etnohistórico como una ruta para la mejor comprensión de la complejidad de la autoadscripción.

Debido a su relación geográfica y social con la urbe no es fácil que actualmente el distrito texcocano sea reconocido como una región con carácter

1. Propuesta conceptual que se describirá más adelante. 
indígena. Esta resistencia puede ser observada tanto en medios académicos especializados como en diversos ámbitos sociales, incluso locales. Sin embargo, inmersos en la coyuntura que ha emplazado la construcción de un proyecto aeroportuario de dimensiones extraordinarias sobre su territorio, los habitantes, pertenecientes a comunidades de ascendencia nahua-acolhua han comenzado a esgrimir, primero en el ámbito legal y luego en otros espacios políticos y sociales, el legado de su cultura como instrumento de lucha. A través de una aproximación etnohistórica a la región constatamos que ésta no es la primera vez que el fenómeno ocurre y es por eso que proponemos estudiar los momentos históricos en que la particularidad cultural y una forma de concebir y organizar su entorno han sido empleados por los pueblos de esta región en la defensa territorial. Advertimos que así como esta instrumentación se evidencia en determinadas coyunturas también han existido momentos en que este sentido de pertenencia ha sido resguardado por los mismos pueblos.

\section{Perspectivas teóricas sobre el concepto de indio y la noción de etnicidad}

Como es de amplio conocimiento, el término indio o indígena fue utilizado por primera vez hace cinco siglos por los europeos para nombrar a los pueblos, tribus y civilizaciones que habitaban el continente americano antes de su llegada. Indiscutiblemente se trata de un concepto histórico y por lo tanto el uso y contenido del mismo es dinámico. El empleo del término indígena ha correspondido a diversos procesos históricos durante más de cinco siglos. La variedad conceptual sobre lo indígena en México es tan amplia que pueden encontrarse en ella desde las nociones que durante el siglo XVI debatieron la existencia del alma de los sujetos pertenecientes a estas poblaciones, hasta las autoafirmaciones contemporáneas sobre la autonomía política y la constitución de los pueblos como sujetos portadores de derechos colectivos, sociales y culturales.

En el ámbito de las ciencias sociales y particularmente en los círculos de los estudios antropológicos, la definición de lo indígena también ha sufrido diversos desplazamientos que van desde las concepciones decimonónicas que lo vinculaban indudablemente a las cualidades biológicas (filiación san- 
guínea y características fenotípicas) a través del uso del concepto de raza, pasando por la validación de criterios como la vestimenta, los hábitos y la residencia rural, hasta los debates actuales acerca de la etnicidad, la agencia de los sujetos y su inherente complejidad interna.

Es fundamental entender que la imposición colonial del concepto indio o indígena alimentó, mediante el discurso y la práctica política cotidiana, dos fenómenos complejos. Por un lado sectorizó bajo un mismo término, poblaciones muy diversas con historias, prácticas y características culturales a veces muy distantes y por otro lado, fragmentó sus posibilidades de reconocimiento mutuo y por tanto de defensa de sus derechos al reducir a lo local la escala de los alcances jurídicos, políticos y geográficos de los nacientes municipios. Siguiendo a Bonfil (1972), distinguimos entonces el término indígena y su concepción histórica colonial de lo que se entiende por identidad étnica o etnicidad.

Trabajos teóricos más recientes han propuesto algunos fundamentos de la etnicidad. Retomamos aquí los planteamientos de D'Andrea (2000). Este filósofo italiano ha propuesto estudiar la sustentada creencia en la consanguinidad, la inmodificabilidad de la pertenencia, la preeminencia sobre otras formas de adscripción, la relativa rigidez de las fronteras del grupo, la amplitud de horizonte temporal de su existencia, es decir una larga memoria histórica compartida y por último, la biologización de la tradición como elementos base para reflexionar estos fenómenos adscriptivos. Sobre el sentido del tiempo y la pertenencia, Hall y du Gay (2003) enfatizaron siempre las proyecciones colectivas de futuro y su papel cohesionador en la constitución de identidades. Finalmente tenemos que referirnos a la importancia de los territorios que, como espacios de significación (Bartolomé, 2010), constituyen el eje de los movimientos actuales entre los pueblos del continente.

Es así que, para referirnos al caso de los pueblos y comunidades estudiadas en este análisis es necesario guiarnos por el contexto histórico en el cual están inscritas. Como lo ha demostrado la historiografía especializada, los pueblos que actualmente habitan la región de la ribera oriental del lago de Texcoco se conformaron durante el período denominado posclásico mesoamericano (entre los siglos XI y XIII e.c.). También se ha documentado que su proceso de asentamiento se produjo en medio de un complejo conjunto de migraciones 
humanas provenientes del noroccidente del actual territorio mexicano. La caída de Teotihuacan y la decadencia de Tula ayudan a entender el patrón de asentamiento y sedentarización en la Cuenca de México de diversos pueblos nómadas comúnmente denominados chichimecas. También ha quedado registro histórico del intrincado intercambio cultural que los investigadores, a lo largo de los siglos han convenido en llamar toltequización de estos grupos. Los procedimientos políticos de alianza mediante enlaces matrimoniales y convenciones territoriales dieron origen a un poderoso señorío en esta región que se ha llamado Acolhuacan. También es posible demostrar que en conjunto con este fenómeno histórico cultural, los pueblos ocupantes de la cuenca en este periodo construyeron un sistema de coexistencia intercultural en donde predominó la cultura mexica y el uso de la lengua náhuatl.

Sin embargo, como se verá en las siguientes líneas, esta particular construcción cultural sufrió, a partir de la conquista y hasta la actual coyuntura, diferentes circunstancias históricas que permitieron a sus portadores el uso y generalmente el resguardo de su identidad étnica como una estrategia de territorialidad y continuidad comunitaria. El carácter subalterno de la región y sus pueblos como se verá, está profundamente marcado por la cercanía geográfica a la urbe más grande y potente económica y políticamente del país.

Contrariamente a las narrativas que en el indigenismo latinoamericano (principalmente el de la primera mitad del siglo XX) describían la pérdida pasiva de ciertas prácticas culturales de los pueblos indígenas y campesinos ante el avance de las políticas integracionistas, de la modernidad y la urbanización y de la transformación que éstos procesos implicaban para la cultura de los pueblos, planteamos aquí la noción de resguardo social. Retomamos y desarrollamos el concepto utilizado por Hugo Ferrer, dirigente comechingón, de la comunidad Pueblo La Toma, Córdoba, Argentina para referir a la 
decisión de sus antepasados sobre la discontinuidad de los rasgos culturales de su pueblo en el espacio urbano. ${ }^{2}$

El resguardo de lo cultural puede ser entendido como una actitud social, consciente y voluntaria que en la vida cotidiana adoptan los subalternos y que tiene como propósito el ocultamiento en el espacio público de ciertos rasgos particulares de la cultura propia para evitar la discriminación en un entorno colonial. Se trata así, de un acto político de carácter estratégico y preventivo en un ambiente desventajoso en el que se pueden generar situaciones discriminatorias. Sin embargo, el carácter vertical de las relaciones interculturales somete a esta práctica a una serie de riesgos para la cultura dominada. La persistencia de mediana duración de esta actitud de resguardo puede llevar al abandono de costumbres y al riesgo de desaparición de estos elementos culturales sobre todo al renunciar al espacio público como lugar para su reproducción. Algunos elementos culturales, como el uso de la lengua materna y el vestido son fáciles de resguardar voluntariamente. Sin embargo, podemos observar que al quedar parapetados en el último círculo de su recreación, el de los ámbitos más íntimos como el familiar, muchos conocimientos, códigos, prácticas culturales y formas de relación social tienden a debilitarse y a acercarse a la pérdida parcial o total y a la imposibilidad de su rescate para la defensa territorial.

2. En el marco del «Taller de investigación e Intervención con organizaciones sociales populares de base territorial con foco en trabajo, producción y acción colectiva» auspiciado por el Centro Latinoamericano de Formación Interdisciplinaria realizado en la Universidad Nacional de Córdoba, Argentina en septiembre de 2017, los asistentes tuvimos oportunidad de conocer las reflexiones de Hugo Ferrer sobre el rescate de la cultura comechingón. Ferrer recalcó que esta tarea no habría sido posible sin la actitud de resguardo como una práctica familiar consciente de protección contra la discriminación en el espacio urbano. Asumo que el uso del concepto en el discurso del dirigente puede estar vinculado a la idea del resguardo indígena comúnmente utilizada en algunas legislaciones latinoamericanas para referirse a los fundos legales comunitarios que la corona española reconoció. Sin embargo, retomamos el concepto en el contexto de la alocución referida desde su sentido sociopolítico para distinguir la voluntad y la conciencia de los sujetos sociales orientada a la autoprotección colectiva. 


\section{Usos y resguardos de la cultura propia. La larga duración de la defensa territorial en Atenco-Texcoco}

La guerra de conquista y la imposición de un sistema colonial produjeron, según Palerm (1972), en esta antigua región con unidad histórica y geográfica, un fenómeno de marginación económica y política con respecto a la Ciudad de México. Texcoco se convirtió en un centro productor de lana y cereales. Esta economía desplazó al maíz y deforestó irremediablemente a la región. El decaimiento económico en relación con la Ciudad de México y la sujeción al nuevo orden político colonial repercutió también en lo social y lo cultural. El sometimiento territorial mediante el sistema de encomienda redujo a los pueblos desde el punto de vista geográfico (nos referimos a la política de reducción o congregación de indios) pero también desde una perspectiva cultural. La centenaria diversidad cultural de la Cuenca fue borrada de la vida cotidiana. A partir del siglo XVI no hubo reconocimiento alguno por parte del poder político novohispano a diversidad identitaria alguna. Así, tepanecas, mexicas, acolhuas, culhuas, chalcas, tlahuicas, xochimilcas... todos, fueron reducidos a indios o indígenas. El nuevo orden social constituyó así esta categoría supraétnica. Pero al mismo tiempo rompió la antigua unidad territorial de regiones como el Acolhuacan. Los pueblos del antiguo señorío fueron incorporados a nuevas dinámicas políticas, sociales, económicas y religiosas que los fragmentaron primero en tres zonas económicas. El llano, el somonte y la sierra. Sin embargo, la fragmentación territorial fue aún más profunda y llegó al nivel municipal y al parroquial.

Así, la adscripción identitaria referida al carácter étnico de los habitantes de la región dejó de ser particular (no se usaron más los referentes clánicos o locativos como mexicas, texcocanos o acolhuas) y comenzó a ser utilizada la terminología colonial. Los pueblos comenzaron a ser llamados indios o indígenas por la burocracia virreinal y los habitantes utilizaron el nombre de sus localidades para autorreferenciarse en la cotidianidad.

El uso del término indígena por los propios pueblos ha dependido desde el siglo XVI de contextos y usos particulares. Así, mientras en un juicio de 
1573 contra los descendientes de Nezahualpilli ${ }^{3}$, los pobladores de la región defendieron su carácter indígena como legítimos herederos de un predio denominado Acatetelco ante las autoridades virreinales (Hicks, 1978); más tarde, luego de la independencia ya en el siglo XIX, hicieron lo opuesto con su identidad y resguardaron su condición indígena.

Durante la primera mitad del siglo XIX diversas disposiciones legales en el Estado de México condicionaron el acceso a los derechos políticos a la aceptación de una nueva terminología autoadscriptiva; en este caso se trataba del uso del término vecino para acceder a la ciudadanía política. Este lineamiento derivó en la desaparición abrupta, en ejercicios censales posteriores, de la población indígena (Birrichaga, 2005). En el mismo sentido estadístico es posible observar la disminución del uso del náhuatl en la región. La cercanía con la capital y la intensidad de las relaciones interétnicas que ésta ha propiciado con el mundo mestizo en un esquema vertical y discriminatorio, lo mismo que la política integracionista instrumentada por el Estado a través de la educación pública, provocaron una consciente y explícita decisión de resguardo de la identidad étnica.

Nomás ya se hablaban poco así en, en la calle, sí, luego nomás entre ellos, nomás los que sabían, los que ya no, pues ya. Se saludaban en náhuatl [...] empezamos a ir más a las escuelas [...] Puro español, ya todos fuimos yendo a las escuelas y se fue perdiendo el náhuatl [...] Ya se hablaba mucho en español, los libros todos en español, pues ya no [...] Dicen que hay libros que manda el gobierno a pueblos donde todavía hablan, pero aquí ya no mandaron nada [...] Uno que otro sí se decía algo, pero casi no [...] porque empezaban a decir «Tú eres indio». Yo muchas veces como seguía hablando, hasta ahora me dice uno «iIndio!», así también me dice [...] Ah, tu todavía eres del tiempo antiguo, tu todavía eres antiguo (Pineda, 2015-2).

La pertenencia a un grupo étnico socialmente discriminado por la estructura jurídica del Estado moderno trajo como consecuencia la pérdida del escaso control político local que los habitantes de los pueblos habían conseguido mantener durante el virreinato. Luego de la independencia, estigmatizados

3. Último gobernante texcocano e hijo de Nezahualcóyotl. Encabezaba al señorío de Acolhuacan al momento de la conquista. 
como analfabetas, los campesinos indígenas fueron desplazados por personas con carácter de ciudadanos, mestizos, y propietarios. La condición cultural particular de estos pueblos fue, para fines prácticos y como consecuencia de estas políticas desventajosas para sus intereses, ocultada por los propios habitantes en medio de la formación del Estado mexicano.

Para el último tercio del siglo XIX la expansión del régimen económico de las haciendas alcanzó a esta región. Numerosas poblaciones fueron despojadas de sus territorios y reducidas a los núcleos poblacionales. La explotación de la mano de obra al interior de las nuevas unidades económicas productoras de cereales y las precarias condiciones de vida de los pueblos, convirtieron a esta región en una de las principales contribuyentes de base social del Ejército Libertador dirigido por Emiliano Zapata. La generación campesina incorporada a las filas de la Revolución Mexicana desde esta región contaba entre sus cuadros de mayor experiencia a algunos combatientes defensores contra la invasión francesa en 1862. Son conocidas en la actualidad las conmemoraciones comunitarias al oriente de la cuenca y en el estado de Puebla que rememoran a través de recreaciones las batallas que los llamados indios zacapoaxtlas libraron contra el ejército invasor.

En la Revolución Mexicana la región de Texcoco fue un lugar estratégico para la defensa y toma de la Ciudad de México, tanto para los objetivos del Ejército Libertador como para el ejército carrancista. La región y sus habitantes tuvieron un papel importante en el desenvolvimiento de la Revolución, sobre todo después de la ruptura de la Convención de Aguascalientes de 1914. Desde principios del año de 1915 el ejército carrancista reinició su avance sobre la Ciudad de México. Su plan era controlar la capital. Sin embargo, el Ejército Libertador mantuvo la defensa y resistencia exterior a la Ciudad sobre las líneas ferroviarias de Puebla a México en el tramo que incluía la región de Texcoco. Estos frentes de resistencia tenían como propósito cubrir la retaguardia de los sabotajes a la línea del ferrocarril entre Texcoco y los Reyes la Paz, municipio hoy conurbado a la Ciudad (Pineda, 2013).

Luego de la guerra revolucionaria, las poblaciones texcocanas, al igual que las de muchas otras regiones del país, iniciaron diversos procesos legales que en la jerga jurídica de la Reforma Agraria se denominaron de restitución de tierras. El proceso burocrático implicaba la presentación de pruebas de 
propiedad previas al establecimiento de las haciendas por parte de los demandantes. Los llamados títulos primordiales expedidos por la administración virreinal en numerosas ocasiones habían sido extraviados a lo largo de la historia por lo que, al igual que en muchos otros casos, los demandantes atenquenses decidieron suplir la falta de documentos con la elaboración de títulos apócrifos. Luego de un juicio desfavorable ante las instancias de la Reforma Agraria los campesinos insistieron en la restitución. Para ello aportaron como evidencia los documentos referentes al juicio de 1573. Finalmente la decisión de los tribunales accedió a la dotación ejidal, mas no a la restitución agraria, lo que implicó el desconocimiento a los habitantes de Atenco como miembros de un pueblo originario por parte de la autoridad (Rosas, 2013). Sin embargo, este pasaje histórico postrevolucionario representa un nuevo uso de la identidad indígena y del legado cultural para, esta vez, recuperar un territorio perdido en el siglo XIX.

Es así que consideramos indispensable la observación del largo y complicado proceso histórico en el que se ha utilizado y en no pocas ocasiones resguardado la identidad indígena en esta región vecina de la capital como un contexto cargado de relaciones de poder. Por tanto, atender este aspecto implicará necesariamente supeditar los factores comúnmente utilizados para la definición contemporánea de las fronteras étnicas a su contextualización.

Aun así, el entramado histórico no sustenta en sí, toda la argumentación autoadscriptiva en la actual coyuntura pues, como veremos más adelante, los pueblos de esta región mantienen piezas fundamentales de sus prácticas culturales e instituciones sociales centenarias dentro de lo que definimos como un ámbito comunitario. Es necesario señalar que estas prácticas e instituciones propias han prevalecido sujetas a la dinámica del cambio histórico y a numerosos procesos de intercambio, apropiaciones e imposiciones culturales pero además de estar circunscritas a las relaciones comunitarias, siempre han estado relacionadas a la continuidad histórica de los pueblos dentro de un mismo territorio. 


\section{El proyecto aeroportuario y los usos de la autoadscripción indígena en Atenco-Texcoco}

En el contexto de la construcción de un nuevo aeropuerto internacional para la Ciudad de México, la realidad de los pueblos afectados ubicados en la periferia urbana de la capital mexicana ha sido ignorada en la discusión política, técnica y económica sobre la pertinencia de este megaproyecto y sus implicaciones para el desarrollo regional. Las comunidades agrupadas en el Frente de Pueblos en Defensa de la Tierra (FPDT), organización social que mantiene su lucha desde el 2001, cuando el gobierno federal intentó por primera vez despojarlas de su territorio para construir una terminal aérea, han interpuesto en los últimos años diversas demandas legales contra los actos de múltiples autoridades que al imponer la obra han violado sus derechos colectivos. La estrategia jurídica de los pueblos incluye ampararse bajo los principios del artículo $2^{\circ}$ de la Constitución Mexicana y como se había apuntado, del Convenio 169 OIT, ambos referidos a los derechos de los pueblos indígenas a ser consultados sobre el desarrollo en sus territorios.

Apenas anunciada la intención de revivir el proyecto de la terminal aérea en el suelo texcocano por parte de la administración de Enrique Peña Nieto en septiembre de 2014, los habitantes de la región, agrupados en el FPDT reivindicaron sus demandas y reactivaron su movilización. Es preciso señalar que el movimiento, si bien había bajado la intensidad de sus movilizaciones no había abandonado su lucha organizada. Como es de conocimiento público internacional, durante el mandato de Peña Nieto como gobernador del Estado de México en mayo de 2006, los tres niveles de gobierno realizaron un operativo policial en el casco urbano de San Salvador Atenco para reprimir al movimiento opositor al aeropuerto. Algunas de las secuelas legales de este operativo llegaron a instancias internacionales como la Corte Interamericana de Derechos Humanos.

Luego de la represión, en la que hubo muertos, violaciones, torturas, detenciones arbitrarias y sentencias de más de cien años contra los dirigentes más visibles del movimiento, el gobierno federal anunció un proyecto ambiental para el vaso del antiguo lago. Bajo esta iniciativa gubernamental, supuestamente ecológica, la oficina federal encargada de la administración de los recursos hidráulicos de la nación, la Comisión Nacional del Agua 
(CONAGUA), inició múltiples procesos de compra-venta a los ejidatarios de las localidades del municipio de Atenco. Algunos posesionarios vieron la posibilidad de vender los terrenos ejidales antes no enajenables, gracias a la cobertura de la reforma al Artículo 27 Constitucional sucedida durante la administración de Carlos Salinas de Gortari (1988-1994).

El Frente de Pueblos previno a los ejidatarios dispuestos a vender sobre las implicaciones para las comunidades pero la idea de un parque ecológico y la oferta económica gubernamental terminaron incidiendo en la decisión de varios campesinos a favor de la venta. Una vez iniciada la administración federal de Peña Nieto (2012-2018), el relanzamiento del proyecto aeroportuario contaba con el control sobre suficientes terrenos ejidales para trazar el polígono del proyecto sobre estos y otros terrenos ubicados en el lecho del antiguo lago y que eran por decreto terrenos administrados por la federación.

Faltaba sin embargo, el dominio sobre muchos predios necesarios para la construcción de autopistas de acceso a la terminal y otras obras de infraestructura de soporte. Para el avance de esta tarea era indispensable un cambio de uso de suelo sobre los terrenos ejidales y una asamblea local era la única facultada para tal cambio jurídico. Fue así que se reactivó el conflicto. La asamblea ejidal se realizó pero fue ampliamente cuestionada por muchos miembros de la misma y por otros habitantes del pueblo y finalmente el hecho fue llevado a los juzgados locales.

Es en esta coyuntura que el FPDT y su equipo de apoyo legal decidieron seguir una ruta en la que se volvió nuevamente necesaria la demostración de su identidad indígena para la defensa de su territorio.

El eje de esta argumentación lo constituye como ya se señaló, el espíritu del artículo $2^{\circ}$ de la Constitución Mexicana que reconoce desde el año 2001 la composición pluricultural del Estado mexicano y además reconoce algunos derechos autonómicos de las comunidades indígenas respecto a su territorio, a su cultura y a sus formas de gobierno. La reforma constitucional, que se dio en el contexto de la movilización política de los pueblos originarios agrupados en el Congreso Nacional Indígena y que acompañaron a la Marcha del Color de la Tierra del Ejército Zapatista de Liberación Nacional en 2001, se convirtió en una camino para cumplir las disposiciones signadas por México en el Convenio 169 de la OIT. 
El instrumento jurídico internacional estatuye que los gobiernos deben asumir la responsabilidad de desarrollar, con la participación de los pueblos interesados, una acción coordinada y sistemática con miras a proteger los derechos de esos pueblos y a garantizar el respeto de su integridad; promoviendo la plena efectividad de los derechos sociales, económicos y culturales de esos pueblos, respetando su identidad social y cultural, sus costumbres y tradiciones, y sus instituciones.

El artículo sexto del mismo convenio contiene el derecho a la consulta, la manera de llevarla a cabo y formas de participación en los órganos públicos de decisión. Los gobiernos deberán, dice el convenio firmado por México:

[...] consultar a los pueblos interesados, mediante procedimientos apropiados y en particular a través de sus instituciones representativas, cada vez que se prevean medidas legislativas o administrativas susceptibles de afectarles directamente. Además: Las consultas llevadas a cabo en aplicación de este Convenio deberán efectuarse de buena fe y de una manera apropiada a las circunstancias, con la finalidad de llegar a un acuerdo o lograr el consentimiento acerca de las medidas propuestas. Los pueblos interesados deberán tener el derecho de decidir sus propias prioridades en lo que atañe al proceso de desarrollo, en la medida en que éste afecte a sus vidas, creencias, instituciones y bienestar espiritual y a las tierras que ocupan o utilizan de alguna manera, y de controlar, en la medida de lo posible, su propio desarrollo económico, social y cultural. Además, dichos pueblos deberán participar en la formulación, aplicación y evaluación de los planes y programas de desarrollo nacional y regional susceptibles de afectarles directamente. (Convenio 169, OIT)

El giro en la estructura legal del Estado mexicano, en el sentido del reconocimiento de los derechos colectivos, sociales y culturales de los pueblos ha originado en las ciencias sociales un renovado interés en el área del pluralismo jurídico. El desarrollo y el interés de esta subdisciplina o área interdisciplinar en México se ha desplazado desde la más básica necesidad de traductores para apoyar a individuos pertenecientes a comunidades indígenas acusados de delitos del fuero común, hasta la actual discusión y diferentes experiencias de intervención sobre casos en que están en juego los derechos territoriales por la ola de megaproyectos que se instauran en los territorios indígenas.

Sin embargo, el entusiasmo que en los miembros del FPDT despertó el seguimiento de esta ruta, contrastó con el escepticismo que causó la estra- 
tegia en el medio académico al que recurrieron. Uno después de otro, varios especialistas e instituciones académicas del área antropológica declinaron intervenir para sustentar la batalla legal del FPDT. En algunas ocasiones las razones de la abstención académica se fundaban en el temor ante un conflicto de dimensiones poco usuales, por ser el aeropuerto el proyecto insignia de la administración federal y por la gravedad de los sucesos que le distinguen en la memoria sociopolítica del país; en otros casos la desmotivación para la intervención académica fue la coacción directa o velada a los especialistas por parte de las dependencias gubernamentales que dotan de empleo a un amplio sector del gremio y que al mismo tiempo eran parte demandada en el conflicto. El Instituto Nacional de Antropología e Historia (INAH) se encuentra demandado en el juicio de amparo interpuesto por los habitantes de la región por haber expedido permisos para la ejecución de la obra en detrimento de la Ley Federal de Monumentos y Zonas Arqueológicas.

Finalmente, como antes se comentó, es posible también encontrar posiciones desdeñosas sobre la línea argumental adoptada en la defensa jurídica del territorio de Atenco-Texcoco. Es sabido que la región no goza de notoriedad entre el círculo antropológico de las últimas décadas por su carácter indígena. El criterio lingüístico ha definido este sesgo en el análisis de los tiempos recientes. Quizá los últimos trabajos etnográficos que estudiaron bajo la perspectiva étnica a la región datan de hace medio siglo (Palerm y Wolf, 1972), justo antes de un palpable aumento en la velocidad de la urbanización en la región y del último marcado crecimiento demográfico y geográfico de la Ciudad de México, tiempo en que el abandono del uso del náhuatl fue drástico en la región.

En las siguientes líneas presentamos una breve descripción del estado del conflicto así como un contexto de la colaboración de un equipo que, al interior del FPDT, se conoce como de antropología, para explicar el origen de este estudio así como algunos de los resultados que sustentan la propuesta interpretativa de este texto.

En septiembre de 2014 inició la colaboración de un equipo interdisciplinario, del cual quien suscribe forma parte, para el sustento de la posición de los pueblos en la disputa legal por el territorio de Atenco-Texcoco contra el proyecto aeroportuario. Este grupo de trabajo involucró a especialistas for- 
mados en áreas diversas. Antropólogos, etnólogos, sociólogos, arqueólogos e historiadores de varias instituciones comenzaron una investigación documental y en campo para construir, hasta ahora, dos dictámenes periciales en materia antropológica y la ampliación de uno de ellos que se consideran medios de prueba en dos juicios.

En los reportes entregados ante dos tribunales distritales, se describen no sólo las líneas históricas de los pueblos que arriba se enuncian sino también la vigencia de numerosos elementos sociales y culturales que se destilan de ese proceso histórico y que constituyen en la actualidad el sustento de una identidad que nosotros tenemos la convicción, posee características nahuasacolhuas y por supuesto comunitarias.

En los estudios se logró comprobar que existen una serie de prácticas económicas, productivas y comerciales, que son tradicionales en las comunidades de la región, las cuales pertenecen a una lógica indígena campesina, distinta a la economía de mercado. Estas prácticas, aunque diversificadas, se fundamentan en el acceso de dichos pueblos a la tierra, el territorio y sus recursos. De acuerdo con la investigación de campo realizada, encontramos que existen prácticas alimentarias, religiosas y medicinales, vinculadas con una cosmovisión mesoamericana, la que, entre otras características, se distingue por la observación del medio ambiente, incluido el ciclo agrícola, lo que deriva en un modo particular de ordenar el entorno y el lugar que el pueblo atenquense y el texcocano ocupan en él. La investigación también encontró que las instituciones sociales de las poblaciones de la región de estudio, conforman una estructura fundamental en la reproducción de su identidad y cultura. Se trata de formas organizativas colectivas que se han construido históricamente y tienen características tanto civiles, como religiosas, propias de estas poblaciones de origen nahua-acolhua. Lo anterior evidencia una dinámica vital de relaciones familiares, comunitarias y regionales que se arraigan íntimamente al territorio y la cosmovisión mesoamericana.

La relación que los pobladores de Atenco y Texcoco mantienen con su historia y su territorio, es y ha sido determinante para la conformación de su cultura que encuentra sus orígenes en el pueblo acolhua, mismo que ha dejado un importante legado a sus descendientes y que puede ser constatado en prácticas específicas como la producción doméstica de autoconsumo, la 
manera de obtener y preparar su alimento, la forma en que llevan a cabo sus prácticas ceremoniales (civiles y religiosas) y en las que se hace presente la importancia del lazo social para organizarse.

En las conclusiones de la investigación argumentamos que sin la relación intrínseca entre comunidades y entorno, no hay identidad ni garantía de la continuidad de los pueblos como tales. Estamos convencidos de que la persistencia de este sistema territorial implica de facto mantener la estructura de los pueblos y su ordenamiento social, económico, religioso, su organización del trabajo y sus expresiones simbólicas. La integridad del territorio de los pueblos de origen acolhua, ha dado certeza y ha permitido la continuidad de estas poblaciones a lo largo de la historia. La investigación realizada no nos dejó dudas acerca de la existencia de un amplio repertorio de rasgos culturales materiales e inmateriales que se tienen en alta estima por parte de los pobladores de la región. Estos rasgos conforman un sistema complejo de relaciones que involucra a la memoria, las relaciones familiares, comunitarias e intercomunitarias, las prácticas económicas, alimentarias, de procuración sanitaria y simbólico-religiosas que han cristalizado en forma de instituciones sociales propias. Dichas instituciones moldean la vida cotidiana y ritual de estas comunidades y fincan sus bases materiales en la relación de los pueblos con su territorio.

La continuidad expresada en este constructo complejo definido para los fines de los peritajes como patrimonio cultural, constituye un argumento sólido y suficiente para concebir a los pueblos de la región como herederos de una ascendencia acolhua de matriz mesoamericana.

Se documentó así mismo información suficiente para afirmar que, contrario al respeto a los derechos de información y de consulta que tienen los habitantes y pueblos indígenas de la región que será impactada por la realización de un proyecto de esta magnitud, las autoridades involucradas han creado un ambiente hostil y de discordia interna que tiende a su conculcación.

A la presentación de los peritajes antropológicos por parte de los pueblos demandantes sucedió la presentación de los estudios propios por parte de las instancias demandadas. Entre estas se encuentran las dependencias de gobierno y también la empresa Grupo Aeroportuario de la Ciudad de México. Los argumentos de los peritos en antropología de las partes demandadas sus- 
tentan una visión estática sobre la identidad. El argumento principal busca la esencia de la identidad en las características culturales adjudicadas por la antropología clásica a los pueblos indígenas tales como la actividad campesina, la vestimenta tradicional y la residencia en poblaciones rurales. En algún pasaje de su reporte, el perito del grupo empresarial remite sus pruebas a la estadística oficial para determinar que no existen indígenas en cinco kilómetros a la redonda del polígono del proyecto. Los datos referidos provienen de la Comisión para el Desarrollo de los Pueblos Indígenas (CDI) y ésta a su vez los toma del Instituto Nacional de Estadística y Geografía (INEGI), instancia que construye la estadística censal sobre pueblos indígenas con base en el principio lingüístico y el autoadscriptivo que desde la perspectiva expuesta en nuestra investigación se consideran insuficientes.

A mediados de 2017 la jueza novena de distrito, la magistrada encargada del expediente del juicio de amparo contra el aeropuerto emitió su sentencia en donde decidió sobreseer los cargos y dar por terminado el proceso sin entrar a la materia de la demanda. Su argumento giró en torno a la falta de pruebas sobre la residencia en los pueblos por parte de los firmantes de la demanda y su falta de acreditación como sujetos implicados en las afectaciones del caso. Medio año más tarde y ante un recurso de apelación de los pueblos, un tribunal colegiado revirtió la sentencia de la jueza y le exigió actuar de buena fe, atendiendo los argumentos y pidiendo una ampliación de las pruebas periciales. En marzo de 2018 se entregó una ampliación del estudio antropológico. Fue esta una oportunidad para profundizar la investigación en fuentes más precisas. La línea argumental sin embargo, siguió la misma ruta.

Entre tanto las obras al interior y exterior del polígono ejecutadas por diversas empresas nacionales y trasnacionales continuaron en abierta violación a diversas sentencias de suspensión. Numerosas denuncias de opacidad presupuestal en las que incluso se ha visto involucrado el Ejército Mexicano como «empresa contratista», de crecimiento exponencial inexplicable de los presupuestos originales, y de triangulaciones de fondos públicos de ahorro para el retiro de los trabajadores como prenda para la continuidad financiera de la megaobra así como las críticas desde diversos sectores a la pertinencia del proyecto no detuvieron las afectaciones. 
Durante 2018 la actividad del FPDT se multiplicó debido a la incorporación al movimiento de varias decenas de comunidades pertenecientes a otros municipios en donde el proyecto generó fuertes impactos ambientales. La depredación de los cerros de la región en la búsqueda de materiales pétreos para el relleno del suelo del lago y el acondicionamiento de pistas y cimientos ha motivado la inconformidad de habitantes de las zonas serranas de la cuenca que se consideraban exentas de impacto. La expansión del anillo de las afectaciones ecológicas orilló a otros pueblos a iniciar rutas similares a los iniciadores del movimiento.

Por otro lado algunos habitantes de la región contigua al polígono, que en un primer momento se habían paralizado ante el inicio de la obra por temor a las represalias, advirtieron que las implicaciones del aeropuerto no quedarían constreñidas a la barda perimetral del mismo. Gradualmente los habitantes de las comunidades descubrieron que la perspectiva empresarial para la región es el establecimiento de zonas residenciales, servicios hoteleros, bodegas y sistemas industriales vinculados estrechamente al comercio internacional así como infraestructura destinada a la manufactura. El plan de desarrollo fue descrito por Carlos Slim, el hombre más poderoso de México y con amplios intereses invertidos en el nuevo aeropuerto, como un detonador fantástico para el desarrollo de sus negocios. La disputa por la región está lejos de terminar.

Como hemos podido observar, el más reciente proyecto de desarrollo para la región de Texcoco es una etapa más y quizá el culmen de un proceso de colonización caracterizado por una guerra de casi cinco siglos, que de manera continua ha ejercido la fuerza de la modernidad, contra el agua en la Cuenca de México. Texcoco y sus casi 10 mil hectáreas verdes representan hoy, en términos medioambientales, el último resquicio en la base del antiguo sistema lacustre para la recarga de los mantos acuíferos en la región. La Ciudad de México ha sufrido recientemente los estragos que le provoca su situación geográfica en una zona de alto riesgo telúrico. Además, los perjuicios que los últimos sismos han causado se han potenciado por la extrema deshidratación del subsuelo. Una docena de fracturas geológicas de dimensiones kilométricas (que han sido estudiadas por décadas y con las cuáles en cierta medida había aprendido a convivir la población urbana) emergieron abruptamente 
a la superficie debido al terremoto de septiembre de 2017 dañando el patrimonio y la vida cotidiana de miles de familias. El panorama de un nuevo centro urbano sobre esta región de conservación natural cuyo centro metropolitano sería el nuevo aeropuerto no permite observar un futuro halagüeño para los más de veinte millones de habitantes que actualmente tiene la megalópolis mexicana.

Los pueblos de la región junto con sus vecinos de las zonas altas que rodean a la cuenca al oriente, sur y poniente de la mancha urbana son a su vez el último refugio para los conocimientos campesinos que durante siglos supieron aprovechar la convivencia con el agua y con el lago convirtiéndose en un cinturón de amortiguamiento a la expansión urbana.

\section{Conclusiones}

A través de estas páginas hemos buscado exponer cómo un sentimiento de pertenencia colectiva con carácter étnico ha sido un valioso instrumental en la defensa del territorio a lo largo de la historia de estos pueblos. Observamos que las coyunturas históricas instaladas bajo la lógica del proceso modernizador en los últimos cinco siglos han ameritado diferentes estrategias en el uso de esta herramienta política que van desde los usos políticos de la identidad hasta los resguardos sociales en situaciones desventajosas. Hoy, diversos sujetos al interior de estos pueblos han madurado su experiencia sobre el uso estratégico de su identidad indígena y han aprendido a emplear los distintos códigos legales para operarlos a su favor en la defensa de su territorio. Aún más, en diferentes reuniones y asambleas comunitarias en la región, que trascienden el espacio nuclear del FPDT pero que coinciden con este en el compromiso histórico que les ha tocado tomar, se discute sobre la necesidad de apropiarse de las herramientas del diagnóstico cultural para identificar, seleccionar, reproducir, recrear y consolidar los elementos culturales propios en la búsqueda de su permanencia y a través de ella de su continuidad como comunidades.

Finalmente, observamos la necesidad de estudiar las particularidades históricas y culturales de los territorios en disputa para comprender mejor los 
rasgos identitarios de los pueblos y comunidades que los ocupan, sus usos políticos y sus resguardos sociales. En el caso de Texcoco-Atenco es evidente que los procesos de resistencia para mantener el control sobre su territorio han llevado a los pueblos a usar su identidad de diferentes maneras y en sentidos diversos. La contigüidad con la Ciudad de México y el proceso urbanizador acelerado durante la segunda mitad del siglo XX no extinguió las particularidades culturales de estos pueblos y hoy estas, se ha convertido en instrumento de su lucha. Este fenómeno obliga a los estudios culturales a distanciarse de los esquemas dicotómicos rural-urbano y de las nociones estereotipadas que cierran los criterios de definición étnica a los rasgos comúnmente aceptados como el lingüístico o el autoadscriptivo. Incluir la escala histórica regional en el estudio de los conflictos actuales permite percibir los múltiples factores que esbozan el desarrollo de la cultura de los pueblos y ampliar las posibilidades de su fortalecimiento.

\section{Referencias}

Bartolomé, M. (2010). Interculturalidad y territorialidades confrontadas en América Latina. Runa. XXXI (1) 9-29. Recuperado de http://www.scielo.org.ar/scielo.php?script=sci_arttext\&pid=S1851-96282010000100001 el 18 de diciembre de 2018.

Birrichaga, D. (2005). Grupos políticos en los pueblos texcocanos, 18201850. México D.F., México: Colegio Mexiquense.

BonfIL, G. (1972). El concepto de indio en América: una categoría de la situación colonial. Anales de Antropología. Vol. 9. 105-124. Recuperado de http://www.revistas.unam.mx/index.php/antropologia/ article/view/23077/ el 18 de diciembre de 2018.

D'ANDREa, D. (2000). Las razones de la etnicidad. Entre la globalización y el eclipse de la política. En Gilberto Giménez, Teoría y análisis de la cultura, Volumen Dos, Conaculta, México.

Dubet, F. (1989). De la sociología de la identidad a la sociología del sujeto. Estudios sociológicos Vol. VII, No. 21, Colegio de México, México.

Hall, S. y du GaY P. (2003). Cuestiones de identidad cultural. Amorrortu, Buenos Aires.

Hicks, F. (1978). Los calpixque de Nezahualcóyotl. Estudios de Cultura náhuatl. Vol. 13. México D.F., México: Instituto de Investigaciones Históricas. Universidad Nacional Autónoma de México. 
Palerm, A. y Wolf, E. (1972). Agricultura de riego en el viejo Señorío del Acolhuacan, en Palerm, A. y Wolf, E., 1972. Agricultura y civilización en Mesoamérica. Editorial. SEP- Setentas. México.

Pineda, F. (2013). Ejército Libertador. 1915, Ediciones Era, México.

Rosas, R. (2013), San Salvador Atenco. Historia agraria (1910-1940), Universidad de Guanajuato, México.

Documentos legales

Artículo $2^{\circ}$ Constitución Política de los Estados Unidos Mexicanos. Recuperado de http://www.diputados.gob.mx/LeyesBiblio/ pdf/1_270818.pdf el 18 de diciembre de 2018.

Convenio 169 Organización Internacional del Trabajo. Recuperado de https:// www.ilo.org/wcmsp5/groups/public/---americas/---ro-lima/documents/publication/wcms_345065.pdf el 18 de diciembre de 2018.

Pineda, I. (2015). Dictamen pericial en materia antropológica. Expediente 400/2014. Tribunal Unitario Agrario del Distrito 23 con residencia en Texcoco, Estado de Mexico.

Pineda, I. (2015-2). Dictamen pericial en materia antropológica, Juicio de amparo indirecto: 14/2015, Juez Noveno de Distrito del Segundo Circuito con Residencia en Ciudad Nezahualcóyotl, Estado de México.

Pineda, I. (2018). Ampliación a dictamen pericial en materia antropológica, Expediente de Amparo: 14/2015, Jueza Novena de Distrito en el Estado de México, Ciudad Nezahualcóyotl. 